strychnine and belladonna is obvious. 3. The nutritive liquid peptone contains soluble protein prepared by means of bromelin, the hydrolytic agent of pine-apple juice. The chief advantage of peptone obtained in this way is that it is free from bitter taste. The preparation also shows diastasic power. According to our analysis the preparation contains 18.65 per cent. of solid matters, but the total nitrogen amounted to only 0.31 per cent. By adding to this preparation a few minims of beechwood creasote and of guaiacol it is made suitable for those suffering from gastric disorders, flatulence, \&c., while it improves nutrition in sufferers from respiratory diseases and diminishes cough.

TURKISH CIGARETTES (SACKVILLE BRAND).

(Alexander Bogugratsiry, 3, Sagkville-street, Pigcadility, LONDON, W.)

These cigarettes have been sent to us on the ground that they are made from carefully selected tobacco leaf and that accordingly they can be smoked without giving rise to irritation. The smoke from them is certainly as free from irritating effects or pungency as we imagine tobacco smoke can be, while the aroma is delicate and pleasing. Moreover, the tobacco is free from dust which we regard as an important point.

OYDER.

(William Gaymer ayd Son, Attheborough, Norfolk.)

That Norfolk can produce excellent cyder is plain from a careful consideration of the qualities of the specimens sent to us by the above firm. The samples ranged according to description from "extra dry" to "sweet," intermediate samples being denominated as "old natural," "natural," "medium dry," "very dry," and so on. We give the analyses of a few selected specimens, the results serving to show the chief variations in the composition of differently designated cyders. The " old natural," for example, gave the following results: alcohol by weight, 7.93 per cent.; extractives, 5.00 per cent.; mineral matter, 0.33 per cent.; sugar, 3.22 per cent.; malic acid, 0.28 per cent.; and acetic acid, $0 \cdot 34$ per cent. Sparkling Pometta (resembling a hock in character but less alcoholic) gave the following results : alcohol by weight, $7 \cdot 27$ per cent.; extractives, $4 \cdot 35$ per cent.; mineral matter, 0.25 per cent. ; sugar, $2 \cdot 77$ per cent. ; malic acid, 0.23 per cent.; and acetic acid, 0.24 per cent. Oldfield perry gave the following results: alcohol by weight, 6.57 per cent. ; extractives, $5 \cdot 70$ per cent.; mineral matter, 0.32 per cent.; sugar, 2.43 per cent. ; malic acid, 0.21 per cent. ; and acetic acid, 0.21 per cent. (as will be seen it contains less sugar than the previous specimens and less alcohol). In no instance did we find the volatile acid, recorded as acetic acid, to exceed 0.34 per cent., which is evidence of the sound condition of the cyders.

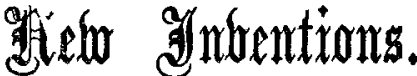

\section{AN EYE PROTEOTOR FOR USE AFTER CATARACT EXTRACTION, WOUND OF EYEBALL, \&C.}

NUMEROUS eje protectors for use after cataract extraction have been suggested by Fuchs, Snellen, and others. For some years I have used a wire protector made for me by Down Bros. Lately I have adopted modified motor goggles and have found them extremely useful. They consist of a detachable calico front piece, to the ends of which a piece of broad tape or elastic is attached. Two round metal rims one and three-quarters inches in diameter and half an inch high are inserted. The sides of these are pierced by numerous holes, for ventilation. The rims are covered with tinted glass. After the cataract operation a thick oblong piece of absorbent cotton wool or Gamgee tissue is placed over each eye ( 3 inches by $2 \frac{1}{2}$ inches) and the protector is tied round the head, the rims resting on the cotton-wool pads. After from two to five days the pad is removed from the eye which has not been operated on, and in from five to eight days from the other eye. The advantages of this protector are: (1) The eye which has been operated on is completely and securely covered and it is impossible to damage the eye by a blow of any kind; (2) the cotton-wool pad can be removed much sooner from either eye as the protector excludes bright light and cold air; (3) no strapping or bandage is required; (4) it is very cool and comfortable ; (5) it is quite aseptic, as the

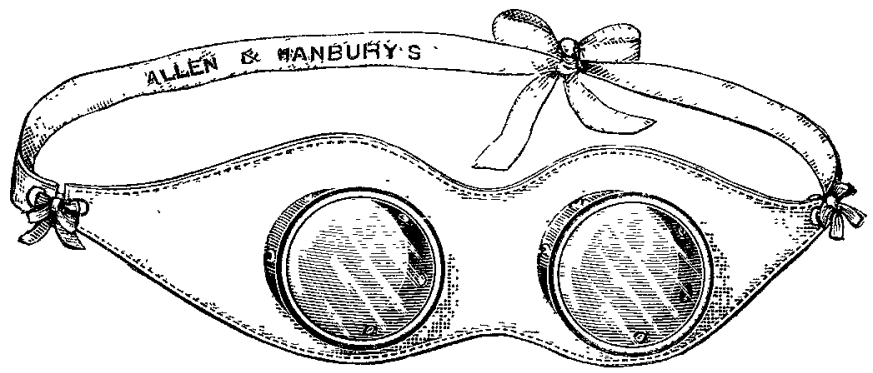

rims can easily be detached and all parts readily sterilised; (6) when the pads are removed no dark glasses are necessary as long as the patient remains indoors; and (7) it is very cheap. The protector is also very useful in the treatment of any eye diseases, operations, and accidents when the eye has to be covered or protected from bright light.

The protector has been made for me by Allen and Hanburys, Limited, of Wigmore-street, London, W.

ADOLPH BRONNER, M.D.,

Senior Surgeon to the Bradford Eye and Far Hospital Laryngologist to the Bradford Roral Infirmary.

Bradford.

\section{A NEW MEDICINAL EVAPORATOR,}

THE apparatus, of which a vertical section is shown in the accompanying illustration, has been devised by Dr. M. Saenger of Magdeburg for the treatment of bronchial and pulmonary diseases by the inbalation of medicated vapours. It consists principally of a circular copper boiler about three inches in diameter and two inches high, supported on three

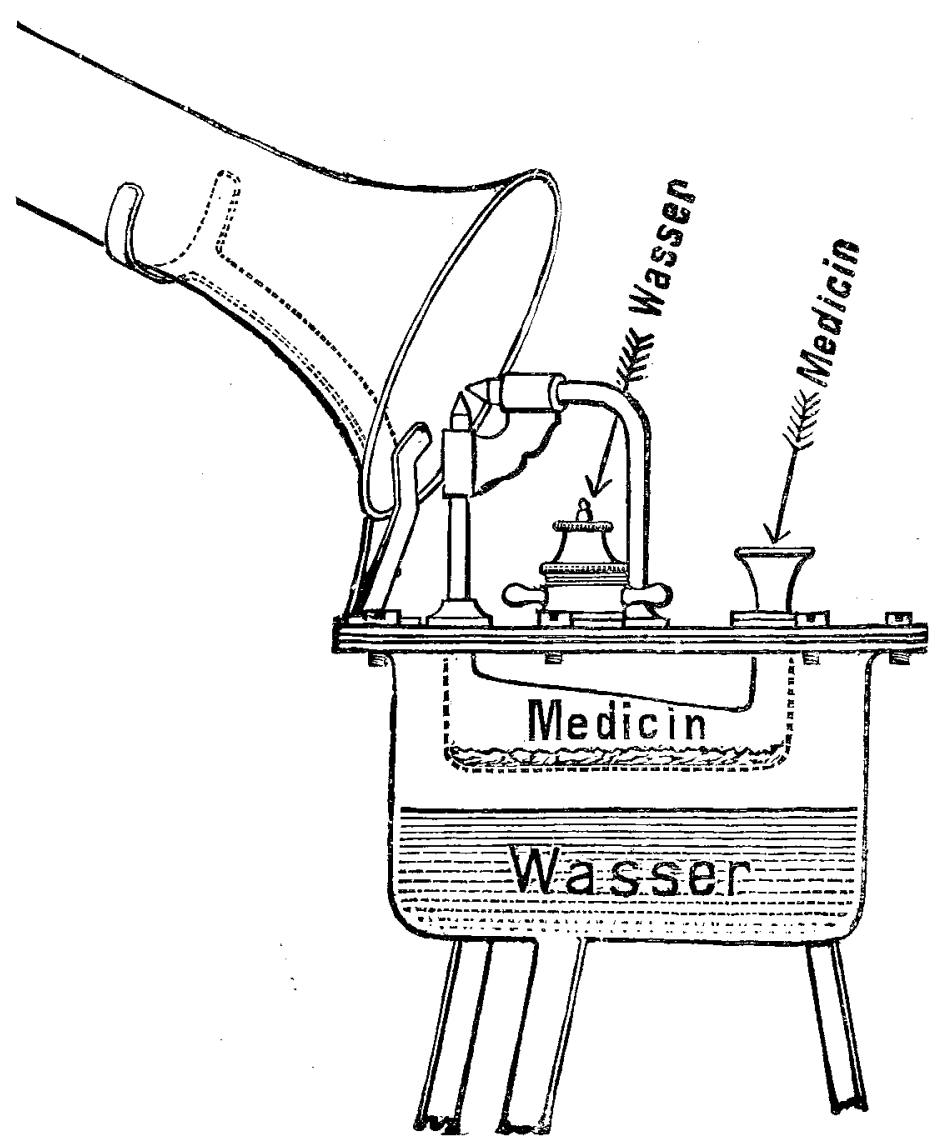

feet of a sufficient length to let a small spirit lamp stand underneath it. On the upper surface there are two inlets, one of which, indicated by an arrow and the German word "Wasser," communicates with the general cavity of the interior, while the other one, also indicated by an arrow, communicates with a separate internal chamber marked "Medicin." Each of these cavities has also an outlet in the form of a fine nozzle. These two nozzles meet at a right angle as shown, under the 